\title{
INFÂNCIAS, JUVENTUDES, UNIVERSOS (AUTO)BIOGRÁFICOS E NARRATIVAS
}


Copyright (C) da Editora CRV Ltda

Editor-chefe: Railson Moura

Diagramação e Capa: Editora CRV

Arte da capa: Mauro Sérgio Neri da Silva

Revisão: Os Autores

DADOS INTERNACIONAIS DE CATALOGAÇÃO NA PUBLICAÇÃO (CIP) CATALOGAÇÃO NA FONTE

I43

Infâncias, juventudes, universos (auto)biográficos e narrativas / Maria da Conceição Passeggi, Zeila de Brito Fabri Demartini, Adelina de Oliveira Novaes (organizadoras) Elizeu Clementino de Souza (direção) Jorge Luiz da Cunha, Ecleide Cunico Furlanetto, Maria da Conceição Passeggi (coordenadores) - Curitiba: CRV, 2018.

222 p. (Coleção: Pesquisa (auto)biográfica, mobilidades, incertezas e refigurações identitárias. v. 3).

\section{Bibliografia \\ ISBN COLEÇÃO 978-85-444-2579-4 \\ ISBN VOLUME 978-85-444-2581-7 \\ DOI $10.24824 / 978854442581.7$}

1. Educação 2. Infância 3. Metodologias 4. Literatura 5. Narrativas I. Passeggi, Maria da Conceição. org. II. Demartini, Zeila de Brito Fabri. org. III. Novaes, Adelina de Oliveira. org. IV. Souza, Elizeu Clementino de. dir. V. Cunha, Jorge Luiz da. coord. VI. Furlanetto, Ecleide Cunico. coord. VII. Passeggi, Maria da Conceição. coord. VIII. Título. IX. Pesquisa (auto)biográfica, mobilidades, incertezas e refigurações identitárias. v. 3.

\section{CDU 37}

Índice para catálogo sistemático

1. Educação 370

ESTA OBRA TAMBÉM ENCONTRA-SE DISPONÍVEL EM FORMATO DIGITAL. CONHEÇA E BAIXE NOSSO APLICATIVO!

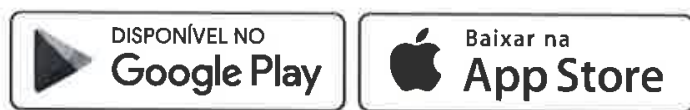

2018

Foi feito o depósito legal conf. Lei 10.994 de 14/12/2004

Proibida a reprodução parcial ou total desta obra sem autorização da Editora CRV

Todos os direitos desta edição reservados pela: Editora CRV

Tel.: (41) 3039-6418 - E-mail: sac@editoracrv.com.br

Conheça os nossos lançamentos: www.editoracrv.com.br

\section{Conselho Editorial: Comitê Científico:}

Aldira Guimarães Duarte Domínguez (UNB) Ana Chrystina Venancio Mignot (UERJ) Andréia da Silva Quintanilha Sousa (UNIR/UFRN)

Antônio Pereira Gaio Júnior (UFRR)

Carlos Alberto Vilar Estêvão (UMINHO/PT)

Carlos Federico Dominguez Avila (Unieuro)

Carmen Tereza Velanga (UNIR) Celso Conti (UFSCar)

Cesar Gerónimo Tello (Univer: Nacion

Três de Febrero/Argentina)

Eduardo Fernandes Barbosa (UFMG)

Elione Maria Nogueira Diogenes (UFAL) Ésisio José Corá (UFFS)

Elizen Clementino de Souzz (UNEB)

Femando Antônio Gonçalves Alcoforado (IPB)

Francisco Carlos Duarte (PUC/PR)

Gloria Fariñas León (Universidade de La Havana/Cuba)

Guillermo Arias Beatón (Universidade de La Havana/Cuba)

Jailson Alves dos Santos (UFRJ)

João Adalberto Campato Junior (UNESP) Josania Portela (UFPI)

Leonel Severo Rocha (UNISINOS)

Lídia de Oliveira Xavier (UNIEURO) Lourdes Helena da Silva (UFV)

Maria de Lourdes Pinto de Almeida (UNOESC)

Maria Lília Imbiriba Sousa Colares (UFOPA)

Maria Cristina dos Santos Bezerra (UFSCar)

Paulo Romualdo Hernandes (UNIFAL/MG)

Rodrigo Pratte-Santos (UFES)

Sérgio Nunes de Jesus (FFR)

Simone Rodrigues Pinto (UNB)

Solange Helena Ximenes-Rocha (UFOPA)

Sydione Santos (UEPG)

Tadeu Oliver Goncalves (UFPA)

Tenia Suely Azevedo Brasileiro (UFOPA)

Este livro foi avaliado e aprovado por pareceristas ad hoc.

\section{Andréia N. Militão (UEMS)}

Diosnel Centurion (Univ Americ. de Asunción/Py)

(Universidad Naciona

Três de Febrero/Argentina)

Eliane Rose Maio (UEM)

Elizeu Clementino de Souza (UNEB)

ston Negreiros (UFPI)

ancisco Ari de Andrade (UFC)

Gláucia Maria dos Santos Jorge (UFOP)

Helder Buenos Aires de Carvalho (UFP)

Passos A. Veiga (UNICEUB)

Âs Ferreira de Souza Bragança (UNICAMP)

José de Ribamar Sousa Pereira (UCB)

Jussara Fraga Portugal

Kilwangy Kya Kapitango-a-Samba (Unemat)

ourdes Helena da Silva (UFV)

ucia Marisy Souza Ribeiro de Oliveira (UNIVASF)

Maria de Lourdes Pinto de Almeida (UNOESC)

Curacia Barreto de Andrade (UFRB)

作

Tônica Pereira dos Santos (UFRJ)

Najela Tavares Ujiie (UTFPR)

Sérgio Nunes de Jesus (IFRO)

Sonia Maria Ferreira Koehler (UNISAL)

urana dos Santos Gomes (UFMG)

Vera Lucia Gaspar (UDESC) 


\section{Sobre a coleção}

A Coleção, Pesquisa (auto)biográfica: mobilidades, incertezas, e refigurações identitárias, tem como propósito socializar resultados de pesquisas que interrogam do ponto de vista teórico-epistemológico as narrativas biográficas e autobiográficas como fontes de pesquisa e de formação. As discussões focalizam modalidades orais escritas, fílmicas, digitais, históricas, literárias e artísticas, inscritas na experiência cotidiana e nos processos humanos de configuração e refiguraçāo identitária, face as incertezas postas no cenário contemporâneo sobre a educação.

A temática, conforme proposta na coleção, desdobra-se, em modos como os sujeitos se movem nas organizações, desorganizaçôes, reorganizaçōes territoriais, de paisagens internas e externas, decorrentes das atuais conjunturas sociais, econômicas, ambientais, culturais, religiosas e políticas, provocadoras de experiências vivenciadas em novos horizontes (auto)biográficos. Tais movimentos ancoram-se em discussōes sobre contextos e conjunturas das mobilidades e processos de refigurações identitárias que se implicam como deslocamentos territoriais, assim como das diversas formas como os sujeitos experienciam, numa perspectiva biográfica, reorganizações impostas pelas fronteiras políticas, econômicas, culturais e humanas que se vinculam aos deslocamentos externos e internos vividos pelos sujeitos.

Os diferentes volumes desta Coleção reúnem contribuiçōes relevantes sobre o estado atual de estudos desenvolvidos no âmbito da pesquisa (auto)biográfica por pesquisadores brasileiros, europeus e latino-americanos, que têm se dedicado a consolidar redes de pesquisa-formação internacional, apontando novos horizontes de investigação em educação, numa perspectiva epistêmico-política, que dão visibilidade e legitimidade à pesquisa científica com narrativas, histórias de vida e memórias pessoai e coletivas que se produzem e circulam em contextos contemporâneos e históricos.

A questão fundante consiste em saber como o humano retraça, narrativamente, as experiências vividas na diversidade de suas condiçōes socioculturais, geracionais, étnicas, profissionais, de gênero, de saúde, de doença, de sofrimento e de superação. Narrativas que se deixam ler, ver, ouvir e sentir como modos de tomada de consciência, formas de resistências e de empoderamento ao biografar tramas e enredos das histórias de sua vida.

A intenção é, portanto, ampliar o debate sobre o enfoque biográfico nas Ciências Humanas e Sociais, ao apresentar contribuições sobre práticas de pesquisa e desafios atuais no campo dos estudos (auto)biográficos em educação e suas interfaces pós-disciplinares.

Elizeu Clementino de Souza Universidade do Estado da Bahia

Jorge Luiz da Cunha Universidade Federal de Santa Maria

Ecleide Cunico Furlanetto Universidade Cidade de Sāo Paulo

Maria da Conceição Passeggi Universidade Federal do Rio Grande do Norte 
Coleçāo

Sumário

Pesquisa (auto)biográfica, mobilidades, incertezas e refiguraçōes identitárias

$$
\text { Direçāo }
$$

Elizeu Clementino de Souza | Universidade do Estado da Bahia | Brasil

\section{Coordenação}

Jorge Luiz da Cunha | Universidade Federal de Santa Maria | Brasil Ecleide Cunico Furlanetto | Universidade Cidade de São Paulo | Brasil Maria da Conceição Passeggi | Universidade Federal do Rio Grande do Norte | Brasil

\section{Conselho Científico}

Adair Mendes Nacarato | Universidade São Francisco | Brasil Ana Chrystina Mignot | Universidade do Estado do Rio de Janeiro | Brasil Andrés Klaus Runge Peña | Universidade de Antióquia | Colômbia Aneta Slowick | Universidade da Baixa Silésia | Polônia Antonio Bolívar | Universidad de Granada |Espanha

Carmen Teresa Gabriel | Universidade Federal do Rio de Janeiro | Brasil Marie Claude Bernard| Université de Laval | Canadá

Christine Delory-Momberger | Université de Paris 13 | França

Christophe Wulf | Universidade Livre de Berlim | Alemanha

Daniel Hugo Suárez | Universidade de Buenos Aires | Argentina Daniel Johnson Mardones | Universidade do Chile | Chile

Dislane Zerbinatti Moraes | Universidade de São Paulo | Brasil

Ercília Braga de Olinda| Universidade Federal do Ceará |Brasil

Filomena Maria de Arruda Monteiro | Universidade Federal de Mato Grosso | Brasil

Gabriel Jaime Murillo Arango | Universidade de Antióquia | Colômbia Gaston Pineau| Université de Tours | França Hervé Breton | Universidade de Tours | França

Inês Ferreira de Souza Bragança | Universidade Estadual de Campinas | Brasil José Antonio Serrano Castañeda | Universidad Pedagógica Nacional | México

José Contreras Domingo | Universidad Barcelona |Espanha José Gonzalez Monteagudo | Universidad de Sevilla | Espanha José Machado Pais | Universidade de Lisboa | Portugal

Juan Mario Ramos Moarales | Universidad Pedagógica Nacional | México Laura Formenti | Universitá degli Studi di Milano-Bicocca | Itália Leonor Arfuch | Universidade de Buenos Aires | Argentina

Luciane De Conti | Universidade Federal do Rio Grande do Sul | Brasil Maria da Conceição Leal da Costa | Universidade de Évora | Portugal Maria Helena Menna Barreto Abrahão | Universidade Federal de Pelotas | Brasil

Maria Teresa Jacinto Sarmento | Universidade do Minho | Portugal

Maria Teresa Santos Cunha | Universidade do Estado de Santa Catarina |Brasil Paula Perin Vicentini | Universidade de São Paulo | Brasil

Peter Alheit | Universidade de Göttingen | Alemanha

Ricia Anne Chansky | Universidade de Porto Rico | Porto Rico

Rodrigo Matos de Souza | Universidade de Brasília | Brasil

Rosemeire Reis da Silva | Universidade Federal de Alagoas | Brasil

Terezinha Valim Oliver Gonçalves | Universidade Federal do Pará| Brasil

Verbena Maria Rocha Cordeiro | Universidade do Estado da Bahia | Brasil

Zeila de Brito Fabri Demartini | Universidade Metodista de São Paulo | Brasil

Prefacio

Antonio Bolivar

\section{Apresentação}

A guisa de introdução. Universos narrativos da

infância e da juventude

Maria da Conceiçāo Passeggi

Zeila de Brito Fabri Demartini

Adelina de Oliveira Novaes

\section{JUVENTUDES E INFÂNCIAS: ENTRE SUBJETIVIDADES, ESCOLHAS E RITUAIS}

Trajetórias biográficas e novas configurações subjetivas

José Machado Pais

Parole d'élèves et subjectivation du parcours

scolaire et d'orientations

Anne Dizerbo

Infâncias e narrativas autobiográficas: cenários

subjetividades e experiências escolares

Simone Maria da Rocha

Maria da Conceição Passeggi

Escolarização prolongada e futuro: percepções a partir de histórias de vida

Maria Teresa Vianna Van Acker

Máximo Augusto Campos Masson

Estudos com jovens/estudantes e pesquisa biográfica Rosemeire Reis

Narrativa e infância. A importância dos contos no ritual iniciático das crianças

Alberto Filipe Araújo

Fernando Azevedo 


\section{NARRATIVAS DA INFÂNCIA: UNIVERSO}

ESCOLAR E CUIDADO HOSPITALAR

Escuelas del futuro como escuelas del presente en imágenes-relatos: el método documental en la interpretación de experiencias conjuntivas de un grupo de niños y niñas de Medellín

Andrés Klaus Runge Peña

Carlos Ospina Cruz

Narrativas infantis sobre seus (des) encontros com o

outro no cotidiano escolar

Luciane De Conti

Escolas da infância. O que contam os professores sobre elas

Iduina Mont'Alverne Braun Chaves

Márcio Mori

O que dizem as crianças do campo sobre a escola

Gilcilene Lélia Souza do Nascimento

Criança indígena e a educação nos grupos-referência

na comunidade Boca da Mata - Roraima

Gilvete de Lima Gabriel

Narrativas de e para crianças: sobre compartilhamentos de representações

sociais no contexto do cuidado hospitalar infantil

Érica Nayla Harrich Teibel

Daniela Barros da Silva Freire Andrade

Sobre as organizadoras

Sobre os autores 


\section{Trajetórias biográficas e novas configurações subjetivas}

José Machado Pais

\section{A polifonia do tempo: gerações e subjetividades}

Costuma dizer-se que cada época tem o seu tempo - havendo mesmo quem aluda a um "espírito do tempo" a cada época inerente. Nesta concepção, que é grata a Durkheim, o tempo objetivar-se-ia na sua externalidade em relação aos indivíduos, impondo-se de forma mecânica e coerciva a todos eles. Tipificado por sua mensurabilidade, o tempo apareceria como padrão de medição quantitativa de uma linearidade histórica. Georg Wilhelm Pinder (1878-1947), historiador de arte, foi dos primeiros pensadores a criticar esta concepção do tempo, insensível às diferenças geracionais, submergidas no espírito do tempo de cada época. Para captar essa pluralidade geracional, Pinder (1928) propõe que seja valorizada a temporalidade polifónica onde ecoam as vozes de distintas geraçōes. E o que identificaria cada geração? Nada mais nada menos do que uma enteléquia própria, um sentimento e atitude perante a vida e o mundo que singularizaria cada unidade geracional. É esta unidade geracional que Pinder contrapõe a uma pretensa unidade do tempo, frequentemente ancorada a um "espírito do tempo". No caso das gerações, tomadas em sua diversidade, teríamos assim uma não contemporaneidade entre contemporâneos.

Contudo, preocupado em sinalizar diferenças geracionais entre distintas geraçōes demográficas, Pinder não deu ouvidos às diferentes vozes que se fazem ouvir numa mesma unidade geracional, desse modo desvalorizando as diferenças intrageracionais. No entanto, teve o mérito - aliás, reconhecido por Karl Mannheim - de chamar à equação da problemática das gerações o tempo vivido subjetivamente, um tempo interior, não mensurável, qualitativo. É este tempo, subjetivamente vivido, que faz com que a problemática das geraçōes deixe de ficar confinada a uma sucessão linear de geraçōes, tomadas num sentido demográfico, para passar a contemplar uma temporalidade interior, vivencial, subjetiva. No entanto, ao jogar as subjetividades na equação da problemática das gerações, Pinder deixou escapar dessa mesma equação a historicidade do social, perdendo também a oportunidade de assumir o fenómeno geracional como um fator intrínseco do dinamismo histórico. Por isso mesmo, Mannheim (1993 [1928]) criticou Pinder por desconsiderar a possibilidade de uma enteléquia social assegurada por uma mediação histórico-social. 
Uma incógnita não satisfatoriamente resolvida na equação da problemática das gerações respeita ao modo como as subjetividades entram nessa equação. É sabido que conceito de subjetividade aparece vinculado a uma realidade subjetiva, a uma maneira de ser e de fazer, de pensar e de sentir, própria de cada um de nós. Falar de subjetividades é falar de experiências de vida que fazem despontar uma consciência de si. Para dar conta do mundo das subjetividades impōe-se um deslocamento de fuga em relação a perspectivas heterológicas que falam do outro desprezando o que o outro frequentemente cala. $O$ outro não pode apenas ser tomado como um mero objeto de estudo. As subjetividades descobrem-se no sujeito que se esconde por detrás da fachada do que aparenta ser. Contudo, há uma outra realidade que se abriga no esconderijo das subjetividades. Por detrás das consciências individuais, razão de ser das subjetividades, o que descobrimos são matizações sociais que legitimam a relevância das subjetividades na problemática das gerações. Por isso mesmo, as configurações subjetivas não podem dissociar-se das configurações sociais. $O$ mapeamento de ambas permite-nos dar conta de distintas disposições geracionais e de possíveis novos rumos societais. Assim sendo, se quisermos explorar novas configurações subjetivas entre os jovens de hoje, temos de ver como elas fluem no caudal do tempo histórico. E mais, temos de ver como as subjetividades individuais se entrecruzam com os scripts ou roteiros culturais.

Um exemplo. Sabemos da relevância da corporalidade, dos afetos, do enamoramento e da sexualidade na construção das subjetividades juvenis. Mesmo em domínios como este, nos quais se jogam os sentimentos de si, as subjetividades não deixam de se construir em sua relação com o mundo. Os seja, se é certo que as subjetividades reclamam uma consciência de si, essa autoconsciência apenas emerge quando o mundo à volta começa a ser pensado e questionado. Pode parecer estranho, mas evocando experiências da minha própria adolescência, somente comecei a questionar seriamente a ditadura salazarista quando, aos 15 anos, me encontrava com a minha namorada de adolescência num banco de jardim, de mãos dadas. Inocentemente, de mãos dadas. Nisto acercou-se um polícia, com voz ameaçadora, ante a suspeita afetividade das mãos dadas. Esta experiência subjetiva, algo traumatizante, fez crescer em mim um sentimento de revolta em relação aos homens de farda. Porém, eles eram apenas a cara visível de um regime repressor. Tinham sido doutrinados para isso mesmo, cumpriam ordens, frequentemente com excesso de zelo. A ordem era assegurada, vim depois a sabe-lo, através de severas coimas que evitariam atentados, perversamente imaginados, contra a moral pública. As multas aumentavam sucessivamente, numa escala de delitos morais que, justamente, começava em mão na māo e evoluía para mão naquilo [órgão sexual feminino]; aquilo [pénis] na mão; aquilo naquilo; aquilo atrás daquilo e com a língua naquilo, o mais penalizado de todos os atentados ao pudor. ${ }^{1}$ Mas acreditem, eu estava apenas com a mão na mão, e longe de mim a intenção ou tentação de ali, num banco de jardim, dar início a uma potencial carreira de delinquente moral.

Por aqui vemos que a subjetividade não corresponde a uma experiência que apenas se circunscreve ao indivíduo. É antes o reflexo de um olhar para o mundo de uma forma simultaneamente vivida e sentida, dando ensejo a que reflexivamente, o possamos interpretar e criticar, potenciando também o desejo de o transformar. E isso acontece porque subjetivamente se ganha uma consciência de si e do que objetivamente se passa no mundo à volta. É essa reflexividade, entre o eu e o mundo à volta de mim, que arma as subjetividades de uma capacidade crítica e potencialmente transformadora, como aconteceu com os movimentos contra culturais protagonizados pela chamada geração de 60 . Porém, se nessa época as subjetividades juvenis de algumas vanguardas contra culturais tinham por base um conflito geracional, uma ruptura em relação aos scripts culturais então dominantes, hoje o que sobretudo sobressai não é tanto uma ruptura em relação ao passado, mas antes a valorização da experiência como condição primordial à descoberta de si (TOURAINE; KHOSROKHAVAR, 2000). O que mais conta é a produção reflexiva de subjetividades mediadas pelas "técnicas do eu", como diria Foucault (2008). Características íntimas da vida pessoal abrem-se a novas experiências, à reivindicação do prazer sexual à escolha de orientações sexuais diversas que se associam a múltiplas construções de subjetividade (BOZON, 2001). Quando a nível cultural os scripts dominantes são questionados é porque a nível intrapsíquico surge uma capacidade desejante que conflitua com esses scripts (SIMON; GAGNON, 2005). A afirmação da individualidade é movida por essa capacidade de desejar. Entre os jovens, o princípio do desejo incentiva gramáticas de vida abertas à experimentação, à afirmação da individualidade. Daí que as novas configurações subjetivas se abram a uma enorme variedade de possibilidades. Os jovens de hoje, muito mais escolarizados do que os de outrora, envolvem-se em múltiplas e diversificadas experiências de vida. Quanto mais reflexivas são essas experiências de vida tanto mais as subjetividades se afirmam.

\section{Horizontes profissionais e novas culturas de trabalho}

Nos últimos anos reacendeu-se o debate sobre o futuro do trabalho, o seu sentido e valor, as suas transformações possíveis, a sua centralidade ou não na vida das pessoas. Ao discutirem-se as novas culturas e trabalho não podemos deixar de questionar, entre os jovens de hoje, o surgimento de um novo ethos criativo (FLORIDA, 2002), outrora associado ao mundo das artes, mas

1 Portaria no 69035/ de 9 de janeiro 1953, da Cammara Municipal de Lisboa, citada por Freire (2010, p. 125-6). 
que agora marca presença em amplos segmentos juvenis (ALMEIDA; PAIS, 2012; CANCLINI; MARITZA, 2012). Jovens criativos laboram no campo das artes, dos livros, da música e das tecnologias digitais, explorando redes de cooperação que prevalecem nas chamadas indústrias culturais. São jovens que fazem parte de uma categoria particular de trabalhadores, nem permanentemente assalariados nem plenamente independentes. Muitos deles trabalham em projetos de curta duração, frequentemente mal pagos, intermitentes, sem contratos de trabalho, sem carreiras estruturadas. Os limitados ganhos que auferem, por falta de encomendas e de contratos de trabalho, favorecem a combinação intermitente de tarefas criativas com atividades secundárias, como constatei numa pesquisa sobre jovens criadores de banda desenhada (PAIS, 2012a). Ao convidá-los para escreverem as suas histórias de vida em quadrinhos verifiquei que a tensão entre vocação e profissão baliza os seus rumos biográficos. A oportunidade de se contarem a si mesmos deu-lhes também ensejo de se conceberem enquanto se contavam. Ou seja, os quadrinhos foram analiticamente usados como decifradores da subjetividade dos seus criadores - tomando-se a subjetividade como um espaço de representação consciencializada. No fundo, pretendia saber em que medida os quadrinhos que os jovens produziam acabavam por os produzir.

O que descobri foi que a criatividade dos jovens produtores de banda desenhada se baseia numa capacidade - feita de astúcias e sagacidades - para interconectar ocorrências, circunstâncias, ideias, oportunidades. Da mesma forma que a banda desenhada é uma arte sequencial, também as trajetórias dos jovens exploram sequências que atingem, por obliquidade, inesperadas consequências. O agir da obliquidade, que é próprio da criatividade e do saber interpretativo dos mundos ficcionais das histórias aos quadrinhos, é uma estratégia explorada por jovens que procuram profissionalizar a sua criatividade. Isto não obstante a desconfiança de pais e professores. Nas palavras de um jovem produtor de quadrinhos, confessar aos pais o sonho de ganhar a vida fazendo bonecos significou dizer "mãe e pai, sou drogado!" Os professores também não eram encorajadores: “ó pá, isso não tem saída! Escolhe outra coisa!" Enfim, diferentes perspetivas geracionais sobre inserções profissionais.

Nas histórias aos quadrinhos como nas histórias de vida surge a tentação da linearidade. Mas a vida comporta descontinuidades, movimentos de reversibilidade, turning points, saltos de vida que reivindicam destreza e astúcias. Há que dominar a arte da pirueta (MCCLOUD, 1993, p. 106) em que se apoia o agir de obliquidade (PAIS, 2012a). Os jovens de hoje encontram-se socializados num jogo de indeterminaçōes de que, aliás, os criadores de banda desenhada deitam mão na produção das suas histórias, quando procuram um ponto de equilíbrio entre a imagem e o texto, o vivido e o percebido, o sonhado e o realizado.
Uma boa parte das novas culturas de trabalho envolvem os chamados trendsetters, jovens criativos que lançam novas tendências no campo da moda das artes ou do marketing. Caçadores de oportunidades, deslocam-se continuamente de um lado para o outro, sem se acomodarem a um emprego estável. Para alguns deles, a mobilidade profissional corresponde a uma escolha biográfica que não se circunscreve à esfera profissional. A mobilidade é encarada como um modo de vida, principalmente se não têm responsabilidades familiares. Estas novas culturas de trabalho, baseadas num ethos criativo e em novas concepções do trabalho, levam alguns jovens a valorizar a flexibilidade e a natureza do trabalho, o ganho que significa não dependerem de horários rígidos. Podem até sentir-se confortáveis com trabalhos temporários que intercalam com viagens de lazer, depois de algumas poupanças. Há quem apresente uma imagem romantizada destes jovens, tocados por um espírito aventureiro que recusa as normas do antigo operariado que buscava um emprego para toda a vida ou do materialismo burguês dos "colarinhos brancos" orientados por uma vida acomodada (STANDING, 2011). Esta rebeldia e inconformismo, tão presentes em amplos sectores juvenis de hoje, constituem um traço cultural de natureza pós-materialista que os distingue de geraçōes predecessoras, muito mais orientadas por valores materialistas. Para estes segmentos de jovens, a valorização da segurança de emprego cede em relação à valorização da realização profissional, da autonomia, da liberdade de exercício de uma atividade profissional liberta da tirania do trabalho subordinado. As chamadas classes criativas prezam estes valores (FLORIDA, 2002).

Como quer que seja, no universo dos trabalhadores temporários há que distinguir entre os precários por opção e os precários por exclusão, provavelmente a maioria deles. No entanto, num ou noutro caso, a criatividade não deixa de ser um apelo à profissionalização. Tome-se o exemplo de um jovem, companheiro de uma doutoranda brasileira que há tempos orientei no Instituto de Ciências Sociais da Universidade de Lisboa. Ela usufruía de uma bolsa de curta duração (bolsa sanduiche, como se diz no Brasil). Agora já é doutorada e professora universitária. O seu companheiro, sociólogo sem bolsa de estudo, nem estudava nem tinha emprego. Poderia ser injustamente classificado como um nem-nem. Na verdade, ajudava a companheira na confecção das refeições. Como bom companheiro virou cozinheiro e tomou-lhe o gosto. Não só da comida, mas das artes de a fazer. No perfil traçado no seu blog, Marido Sanduiche ${ }^{2}$, vemos como a sua passagem por Portugal foi determinante para acalentar uma vocação. Foi em Lisboa que descobriu os sabores da culinária portuguesa e, a partir daí, decidiu que o seu futuro profissional seria jogado no universo da gastronomia. Passado um ano regressou com a sua companheira a Porto Alegre, onde

2 Disponivel em: $<$ http://maridosanduiche.blogspot.pt/>. Acesso em: 30 maio 2018. 
realizou um curso de cozinheiro. Depois seguiu-se um estágio num dos mais conceituados restaurantes franceses do sul do Brasil. Há tempos enviei-lhe uma mensagem, perguntando-lhe como ia a vida. Respondeu-me: "Minha formação acadêmica facilitou muita minha inserção no mercado de trabalho. Meu blog foi fundamental para chegar onde cheguei. Atualmente estou trabalhando no melhor restaurante português do Rio de Janeiro, sou Subchefe lá. Além disso dou aula de cozinha portuguesa também. Estou adorando."

Uma mão na cozinha para ajudar a companheira abriu-lhe a porta de acesso a uma inesperada realizaçāo profissional. Provavelmente a arte culinária acompanhá-lo-á para toda a vida. Estas estratégias de busca de emprego, aproveitando criativamente as oportunidades contingenciais da vida, merecem reflexão quando debatemos as novas culturas do trabalho. A enorme flexibilidade, instabilidade e imprevisibilidade do mercado de trabalho é propícia ao desenvolvimento destas estratégias. Que significado têm, por exemplo, as políticas de formação contínua ao longo da vida? Seguramente, uma necessidade de ajustamento da oferta educativa às rápidas mutações do mercado de trabalho, às transições de vida não lineares (PAIS, 2001; RAFFE, 2003). Não estou, porém, a sugerir que a oferta educativa tenha de ir atrás das demandas do mercado de trabalho.

As chamadas engenharias subjetividade têm também sido apontadas como estratégia de inserção profissional e de fuga ao desemprego (PASCUAL et al., 2012). Elas radicam na vontade dos indivíduos para, autonomamente, forjarem o seu próprio destino. Nelas surge a crença de que quem em suas decisões demonstra uma reflexividade de ação (ADAMS, 2003, 2006; THREADGOLD; NILAN, 2009) está muito mais capacitado a fazer escolhas biográficas (BRANNEN; NILSEN, 2005) ou a gerir os riscos de futuro (ELLIOTI, 2002; LAUGHLAND-BOOY et al., 2015). Estas engenharias da subjetividade poderāo estar redundando em inesperadas oportunidades de vida, balizadas por novas culturas de trabalho, onde se destacam valores de autonomia, improvisaçāo, criatividade, expertise, expressividade e ludicidade (ALMEIDA; PAIS, 2012). Um sugestivo exemplo é o dos já referidos jovens trendsetters. Muitos deles têm conseguido esquivar-se aos dissabores do desemprego. E mais, capazes de trilharem trajetórias de vida marcadas por algumas opções biográficas, eles procuram valorizar o trabalho como domínio de realização pessoal. A sua criatividade é um trampolim para transcenderem o presente e se projetarem no futuro, desse modo tornando presente o futuro. Porém, a natureza estrutural do desemprego continua a ameaçar jovens que de maneira nenhuma poderão ser acusados de padecerem de uma patologia da vontade. Se a vontade dos jovens é determinante para, com autonomia, forjarem o seu próprio destino, não podemos menosprezar as condições sociais que criam ou bloqueiam as estruturas de oportunidade - sobre as quais as políticas de emprego não podem deixar de atuar. Tenha-se em conta que o desemprego tem duas faces: é uma realidade individual, subjetivamente vivida; mas é sobretudo uma realidade com determinantes sociais.

\section{Redes sociais e subjetividades cosmopolitas}

No mosaico das novas configurações subjetivas proporia uma distinção entre subjetividades egocentradas e sociocentradas. As primeiras tendem a centrar-se em si mesmas, ainda que possam reclamar uma projeção social, como acontece com as subjetividades narcísicas. Neste caso, as subjetividades projetam-se no social para melhor afirmarem uma singularidade de cunho individualista. Em contrapartida, as subjetividades sociocentradas singularizam-se por uma adesão a causas sociais. Tais subjetividades reforçam reflexivamente a consciência de si ao projetarem-se numa consciência social. Em uma de minhas pesquisas sobre subjetividades juvenis e horizontes profissionais, acompanhei um jovem brasileiro que, emigrado em Lisboa, vendia num motociclo hambúrgueres vegetarianos. Dizia ele que a escolha do negócio tinha correspondido a uma opção ideológica, pois sabia que para se produzir um quilo de carne se gastavam dois mil litros de água enquanto vinte litros bastavam para produzir um quilo de trigo. Eram preocupações ambientalistas que o levavam a vender hambúrgueres vegetarianos, argumentando ainda que eram mais saudáveis para quem os consumia (PAIS, 2012a, p. 177-181).

Como vemos, o crescente individualismo contemporâneo não impede o ressurgimento, particularmente entre jovens, de formas coletivas de participação social que permitem a afirmação de subjetividades sociocentradas. Podemos dar o exemplo dos mutirões que, em suas origens, envolviam trabalhos agrícolas recíprocos e coletivos, gerando sentimentos de coesão e reforço de laços comunitários. Estas formas colaborativas entraram depois em declínio por colidirem com novas racionalidades económicas baseadas no individualismo. No entanto, a consciência das desigualdades e injustiças sociais atualmente existentes originou o ressurgimento dessas ações coletivas, agora já não centradas numa base de ajuda ou sobrevivência económica. Hoje, os mutirões transformaram-se em mobilizações de natureza política tendo em vista a resolução de problemas ou reivindicaçōes de natureza social. No Brasil, descobri várias ações coletivas orientadas por causas ambientais, como é o caso, de mutirões agroflorestais para plantação de árvores e cuidado das florestas; mutirões para a remoção de lixo nas vias públicas ou mutirões para a reciclagem de lixo electrónico. Também descobri mutirões para ocupação de terras; para a pavimentação de ruas; para cirurgias hospitalares; para garantir e promover os direitos dos reclusos; para arrecadação de verbas a doar 
a vítimas da chuva; para investigar os gastos excessivos e ilegais dos deputados; para a retificação de nomes de transexuais e travestis; para banho a animais carenciados, etc. Muitos destes mutirōes contam com a participação ativa de jovens. As subjetividades sociocentradas movem-se nestes coletivos sociais, buscam soluções coletivas para os problemas da vida cotidiana, exploram novos espaços de autorrealização, na base de compromissos ético e sociais.

Um dos traços mais marcantes das novas configurações subjetivas refere-se ao facto de os jovens de hoje integrarem uma geração mais desterritorializada: viajam muito mais, saem frequentemente aos fins-de-semana, têm uma grande familiaridade com as novas tecnologias da comunicação, movimentam-se numa mais alargada constelação de redes sociais. A participação nestas redes sociais, gerando múltiplas trocas e interdependências, tem tido um crescente impacto na produção de subjetividades que beneficiam de um mais alargado universo de experiências. Os jovens de hoje distinguem-se pelo seu cosmopolitismo, ao envolverem-se em formas de participação social e política de natureza transnacional, frequentemente mediadas pelas novas tecnologias de comunicação (BECK, 2006; COHEN; VERTOVEC, 2008).

É certo que existe um cosmopolitismo banal que poderíamos caracterizar, como diria Guattari (1996 [1992]), por uma produção massiva de subjetividades embrutecidas e infantilizadas pelos meios de comunicação de massas. Neste figurino, a solidez relacional é substituída pela contingência, a unidade identitária pela fragmentação, a autenticidade pelo artifício. A sinceridade perde significado e dilui-se na indeterminação, dando lugar a uma "personalidade pastiche" que, como a define Gergen (1977), toma por empréstimo fragmentos de identidade de qualquer origem, adequando-os às circunstâncias. Neste registo, a existência joga-se nas fronteiras da aparência. Esta cultura da simulação é o suporte de subjetividades simuladas, submetidas às tiranias da visibilidade (AUBERT; HAROCHE, 2011). Ou seja, as novas configuraçōes subjetivas não se traduzem, necessariamente, em emancipação social. No entanto, ao cosmopolitismo banal há que contrapor um cosmopolitismo reflexivo, da natureza crítica, libertadora, participativa (BECK, 2006). Trata-se de um cosmopolitismo enraizado em valores e ethos sociais, atreito a subjetividades sociocentradas. Os jovens são protagonistas destas subjetividades cosmopolitas, expressão de uma consciência de si vinculada a uma consciência cosmopolita da humanidade. Como bem sublinhou Guattari (1996 [1992], p. 24), "A nossa sobrevivência neste planeta está ameaçada não somente por degradações ambientais, mas também pela degeneração do tecido de solidariedades sociais e de modos de vida psíquicos que convém reinventar". As novas configurações subjetivas parecem estar abertas a esta "refundação do político" que, segundo Guattari, deve passar pela valorização das ecologias do ambiente, do socius e da psique.
Por ocasião das manifestaçōes dos jovens indignados em Lisboa e Madrid nos inícios da presente década, particularmente nas acampadas de 2011, eram abundantes os folhetos, cartazes e cânticos reclamando uma nova ordem social, novas éticas de vida, novas sensibilidades culturais: apelos à defesa do meio ambiente e dos produtos biológicos, com mostras de produtos naturais, hortas biológicas e materiais reciclados; reivindicação do "direito à semente", do cuidar da terra, de uma vida em comunidade; defesa de uma cultura da partilha, mesmo no campo gastronómico, com workshops e bancas multiculturais de sabores; apologia dos direitos dos animais; murais com mensagens transformando o espaço público numa arena de comunicação; apelos à defesa dos direitos dos imigrantes; defesa da liberdade sexual e das minorias estigmatizadas; apelos aos valores do amor e da espiritualidade (DAGNAUD, 2011; PAIS, 2012b , p. 269). Manifestaçōes deste tipo condensam experiências múltiplas, vozes de protesto, memórias, aspiraçōes coletivas, tudo apontando para uma refundação do político e a redescoberta novos sentidos de vida.

As subjetividades cosmopolitas decorrem de processos de socialização onde as singularidades individuais se afirmam tanto mais quanto mais inscritas em círculos alargados de socialização. Esta correlação foi evidenciada por Simmel (1977 [1908], p. 425-478 e p. 741-808) em sua teoria dos círculos sociais. A individualidade do ser e do fazer cresce, em geral, à medida que se ampliam os círculos sociais em que se participa. Quanto mais um jovem participa em círculos sociais alargados, tantas mais possibilidades existem para a afirmação de subjetividades enriquecidas por experiências interativas em diferentes mundos sociais. A vida em círculos alargados de ação recíproca produz uma distinta consciência de si, de um si cosmopolita (ABOULAFIA, 2001; GÉRÔME, 2012).

\section{Rematando}

Nas suas trajetórias biográficas os jovens vivem num campo de jogo de possibilidades indeterminadas mas possíveis, entre predestinação e autodeterminação, ordem estabelecida e aleatoriedade. Nesse mundo de incertezas, os possíveis emergem de brechas de oportunidade que, obliquamente, possibilitam interconectar ocorrências, circunstâncias, ideias, ressonâncias. Este agir da obliquidade, que encontramos em vários quadrantes do universo juvenil, traduz-se na capacidade de os jovens se adentrarem, olharem para si mesmos, a partir de um fora enriquecido por experiências cosmopolitas e, ao mesmo tempo, de se projetarem para fora a partir de dentro. Esta reflexividade é atributo de novas configuraçōes subjetivas que permeiam múltiplos percursos juvenis. No entanto, tas biografias reflexivas não caminham à revelia dos constrangimentos sociais $\mathrm{O}$ universo das escolhas encontra-se desigualmente distribuído e, ademais, os jovens são frequentemente compelidos a fazer escolhas que não desejariam. 
Como quer que seja as novas configurações subjetivas que pautam as trajetórias biográficas de muitos jovens parecem sinalizar novos rumos societais e novos horizontes de profissionalização. Tenha-se em conta que, para os pais de muitos dos jovens de hoje, possuir uma carreira profissional significava deter uma identidade estável e reconhecida. Em contrapartida, as experiências profissionais dos jovens são atualmente feitas de percursos ziguezagueantes, variáveis e indetermináveis. Os jovens confrontam-se assim com o desafio de se adaptarem a circunstâncias de vida mutáveis - o que pressupõe uma capacidade de ajuste, um saber caçar oportunidades, uma mão cheia de perícias para ultrapassar a contradição entre a calculabilidade do futuro e a previsibilidade do fortuito.

As políticas de emprego têm sido, regra geral, políticas de remendagem. Ora se dirigem ao funcionamento do mercado de trabalho, promovendo, por exemplo, uma maior flexibilização contratual, ora se orientam para uma formaçāo compensatória cujos reais efeitos não têm sido devidamente avaliados. Faltam políticas criativas que tomem os jovens como agentes de inovação e de mudança social, políticas que não se limitem a ficar amarradas às persistências do mercado de trabalho, mas que atuem fora dele para que nele melhor se possam repercutir. Refiro-me a políticas económicas e culturais que, articuladas às ciências e às tecnologias, deem suporte aos desafios de criatividade a que os jovens são sensíveis.

Voltando a Mannheim, as gerações inscrevem-se numa dinâmica histórica que favorece a aparição de grupos de jovens que se diferenciam radicalmente dos seus antepassados. Especialmente em tempos de crise (MANNHEIM, 1946 [1943]), os jovens perfilam-se como potenciais agentes da mudança social. Eles desafiam-nos a questionar a realidade muito para além do que a pressupomos. No entanto, os jovens apenas constituem uma geraçāo de mudança quando ela própria é produto e motor de mudança. Segundo Mannheim (1993 [1928]), há um fator determinante na transformação de uma geração potencial em geração efetiva: a participação no destino comum de uma unidade histórica e social. Para o efeito, não basta que os jovens partilhem de uma mesma situação de geração. Nessa situação, eles apenas conseguiriam ser tragados pelo redemoinho das transformaçōes sociais. A possibilidade para que surja uma nova enteléquia de geraçāo decorre de uma característica dos tempos que correm: uma aceleração no ritmo das transformações sociais e culturais de que aliás os jovens têm sido protagonistas, ao abraçarem subjetividades cosmopolitas que estão na base de novas configurações subjetivas. Estaremos num ponto de viragem?

\section{Referências}

ABOULAFIA, Mitchell (Ed.). The Cosmopolitan Self: George Herbert Mead and Continental Philosophy. Urbana e Chicago: University of Illinois Press, 2001.

ADAMS, Matthew. "Hybridizing habitus and reflexivity: Towards an under standing of contemporary identity?". Sociology, v. 40, n. 3, p. 511-528, 2006.

"The reflexive self and culture: a critique", British Journal of

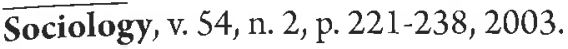

ALMEIDA, Maria Isabel Mendes de; PAIS, José Machado (Eds.). Criatividade Juventude e Novos Horizontes Profissionais. Rio de Janeiro: Zahar, 2012.

AUBERT, Nicole; HAROCHE, Claudine. Les Tyrannies de la Visibilité. Être vsible pour existir? Toulouse: Editions Érès, 2011.

BECK, Ulrich. Cosmopolitan Vision. Cambridge: Polity Press, 2006.

BOZON, Michel. "Orientations intimes et constructions de soi. Pluralité et divergences dans les expressions de la sexualité", Sociétés Contemporaines, Paris, L'Harmattan, n. 41-42, p. 11-40, 2001.

BRANNEN, J.; NILSEN, A. Individualization: Institutionalized Individualism and its Social and Political Consequences. Cambridge: Polity Press, 2005.

CANCLINI, Néstor García; URTEAGA, Maritza (Coords.). Cultura y Desarrollo. Una Visión Crítica desde los Jóvenes. Buenos Aires: Paidós, 2012.

COHEN, Robin; VERTOVEC, Steven (Dir.). Conceiving Cosmopolitanism: Theory, Context and Practice. Oxford: Oxford University Press, 2008.

DaGnaud, M. "Qui sont les Indignés de la Puerta del Sol?", Telos, 13 de Junho, 2011.

ELLIOTT, A. "Beck's sociology of risk: a critical assessment", Sociology, v. 36, n. 2, p. 293-315, 2002.

FLORIDA, Richard. The Rise of the Creative Class. London: Basic Books, 2002. 
FOUCAULT, Michel. Tecnologías del Yo y Otros Textos Afines (Introdução de Miguel Morey). Buenos Aires: Paidós, 2008

FREIRE, Isabel. Amor e Sexo no Tempo de Salazar. Lisboa: A Esfera dos Livros, 2010.

GERGEN, Kenneth J. El Yo Saturado. Dilemas de Identidad en el Mundo Contemporáneo. Barcelona: Paidós, 1997.

GÉRÔME, Truc. "Le soi cosmopolite. Cosmopolitisme et conscience de soi chez Simmel et Mead", Cahiers philosophiques, n. 128, p. 59-70, 2012.

GUATTARI, Félix. Caosmosis. Buenos Aires: Ediciones Manantial, 1996 [1992].

LAUGHLAND-BOOY, Jacqueline; MAYALL, Margery; SKRBIS, Zlatko. "Whose choice? Young people, career choices and reflexivity re-examined", Current Sociology, v. 63, n. 4, p. 586-603, 2015.

MANNHEIM, Karl. Diagnostico de Nuestro Tiempo. México: Fondo de Cultura Económica, 1946 [1943].

. "El problema de las generaciones", Revista Española de Investigaciones Sociológicas, n. 62, p. 193-242, 1993 [1928].

MCCLOUD, Scott. Understanding Comics. The Invisible Art. New York: Harper Collins Publishers, 1993.

PAIS, José Machado. "A esperança em geraçōes de futuro sombrio", Estudos Avançados, USP, São Paulo, v. 26, n. 75, p. 267-280, 2012b. Disponível em: <http://www.scielo.br/pdf/ea/v26n75/18.pdf>. Acesso em: 16 maio 2018. Ambar, 2001

Ganchos, Tachos e Biscates: Jovens, Trabalho e Futuro. Porto:

. "O mundo em quadrinhos: o agir da obliquidade". In: ALMEIDA, Maria Isabel Mendes de; PAIS, José Machado (Eds.). Criatividade, Juventude e Novos Horizontes Profissionais. Rio de Janeiro: Zahar, 2012a. p. 143-185.

PASCUAL, Amparo Serrano et al. "Ingenierías de la subjetividad: el caso de la orientación para el empleo", REIS - Revista Española de Investigaciones Sociológicas, 138, p. 41-62, Abr.-Jun. 2012.
PINDER, Wilhelm. Das Problem der Generationen in der Kuntgeschichte Europas, Leipzig: Seemann, 1928 [1927]. Disponível em: <http://digital. ub.unipaderborn.de/ihd/content/titleinfo/2426186>. Acesso em: 16 maio 2018.

RAFFE, David. "Pathways linking education and work: a review of concepts, research and policy debates", Journal of Youth Studies, v. 6, n. 1, p. 3-19, 2003

SIMMEL, Georg. Sociología, 2. Estudios sobre las Formas de Socialización. Madrid, Revista de Ocidente, 1977 [1908].

SIMON, Wiliam; GAGNON, John H. Sexual Conduct: The Social Sources of Human Sexuality. New Brunswick NJ: Aldine Transaction Publishers, 2005.

STANDING, Guy. The Precariat. The New Dangerous Class. Londres: Bloomsbury, 2011 .

THREADGOLD, Steven; NILAN, Pam. "Reflexivity of contemporary youth, risk and cultural capital", Current Sociology, v. 57, n. 1, p. 47-68, 2009.

TOURAINE, Alain; KHOSROKHAVAR, Farhad. La Recherche de Soi. Dialogue sur le Sujet. Fayard: Paris, 2000. 


\section{Sobre os autores}

\section{Alberto Filipe Araújo}

Professor Catedrático do Instituto de Educação da Universidade do Minho (Braga, Portugal). Doutor em Educação pela Universidade do Minho. Membro do Centro de Investigação em Educação (CIEd) do Instituto de Educação da Universidade do Minho. Áreas de pesquisa científica: Filosofia da Educação; Estudos do Imaginário e História das Ideias Educativas. E-mail: afaraujo@ie.uminho.pt

\section{Andrés Klaus Runge Peña}

Professor Titular do Mestrado e Doutorado en Educación da Universidad de Antioquia. Professor convidado do Doutorado en Ciencias Sociales, Niñez y Juventud da Universidade de Manizales. Doutor en Ciência da Educação pela Universidade Livre de Berlin. Pós-doutorado no Programa de Investigación en Ciencias Sociales, Niñez y Juventud (CLACSO). Coordenador do Grupo de Investigación sobre Formación y Antropología Pedagógica e Histórica. Pesquisador do GRIFARS-UFRN-CNPq. E-mail: andres.runge@udea.edu.co

\section{Anne Dizerbo}

Professora colaboradora de ensino e de pesquisa da Universidade de Rouen. Pesquisadora associado dos Laboratórios de pesquisa CIRNEF (Centre interdisciplinaire de Recherche Normand en Education et Formation) e EXPERICE (Centre de Recherche Interuniversitaire Expérience Ressources Culturelles Éducation) da Universidade de Paris 13 Sorbonne Paris Cité. Seus estudos interrogam a experiência subjetiva de alunos apoiando-se sobre sua capacidade de reflexão. Pesquisadora associada do GRIFARS-UFRN-CNPq. E-mail: dizerbo@gmail.com

\section{Carlos Ospina Cruz}

Doctor en Educación, Rector de la Institución Educativa Rodrigo Arenas Betancur del municipio de Medellín y profesor de la Maestría en Educación y del Departamento de Pedagogía de la Universidad de Antioquia (Medellín, Colombia). Miembro del Grupo sobre Formación y Antropología Pedagógica e Histórica (FORMAPH).E-mail: carlosospinacruz@gmail.co; carturo.ospina@ udea.edu.co 


\section{Daniela Barros da Silva Freire Andrade}

Professora associada do Departamento de Psicologia e do Programa de Pós-Graduação em Educação da Universidade Federal de Mato Grosso, campus Cuiabá. Doutora em Psicologia da Educação pela Pontifícia Universidade Católica de São Paulo. Coordenadora do Grupo de Pesquisa em Psicologia da Infância - GPPIN. Pesquisadora associada ao Centro Internacional de Estudos em Representações Sociais e Subjetividade-Educação (CIERS-Ed) E-mail: freire.d02@gmail.com

\section{Érica Nayla Harrich Teibel}

Professora substituta do Departamento de Psicologia da UFMT. Doutora em Educação pela Universidade Federal do Mato Grosso. Pesquisadora associada do Grupo de Pesquisa em Psicologia da Infância - GPPIN - UFMT e do Núcleo de Educação Permanente em Saúde da Secretaria Municipal de Saúde de Cuiabá-MT. E-mail: ericanayla@yahoo.com.br

\section{Fernando Azevedo}

Professor do Instituto de Educação da Universidade do Minho (Braga, Portugal). Coordenador de unidades curriculares da Pós-graduação em Literatura Infantil e Juvenil, Didática e Formação de Leitores. Orientador do doutorado em Estudos da Criança / Literatura para a Infância. Doutor em Ciências da Literatura. Membro do Centro de Investigação em Estudos da Criança (CIEC). Coordenador da linha de pesquisa "Produções Culturais para as Crianças". Integra o Observatório de Literatura Infanto-Juvenil (OBLIJ) e a Rede Internacional de Universidades Leitoras (RIUL).E-mail: fraga@ie.uminho.pt

\section{Gilcilene Lélia Souza do Nascimento}

Doutora em Educação pelo Programa de Pós-Graduação em Educação da Universidade Federal do Rio Grande do Norte. Pesquisadora associada do Grupo de Estudos e Pesquisas com Narrativas (Auto)Biográficas em Educação (GEPNAE-UFERSA). Pesquisadora do GRIFARS-UFRN-CNPq. E-mail: lelianascimento@ufersa.edu.br

\section{Gilvete de Lima Gabriel}

Professora da Universidade Federal de Roraima. Doutora em Educação pela Universidade Federal do Rio Grande do Norte. Líder do Grupo de Estudos e Pesquisas Autobiográficas, Interdisciplinares e Interculturais de Roraima. PósDoutoranda em Educaçāo na Universidade Federal da Paraíba. Pesquisadora do GRIFARS-UFRN-CNPq. E-mail: gilvetelima@yahoo.com.br

\section{Iduina Mont'Alverne Braun Chaves}

Professora do Programa de Pós-Graduação em Educação da Universidade Federal Fluminense (UFF). Diretora do Colégio Universitário Geraldo Reis (UFF). Doutora em Educação pela Universidade de São Paulo. Doutorado Sanduíche na Universidade de Illinois, USA. Líder do Grupo de Pesquisa Cultura, Imaginário, Memória, Narrativa e Educação (CIMNE/ UFF/CNPq). Pesquisadora Colaboradora do Centre de Recherche en Education de Nantes (CREN), França. Pesquisadora do GRIFARSUFRN-CNPq.E-mail: iduina@globo.com

\section{José Machado Pais}

Professor, pesquisador e Coordenador do Instituto de Ciências Sociais da Universidade de Lisboa. Diretor da Imprensa de Ciências Sociais. Professor Visitante em universidades europeias e sul-americanas. Agraciado com o Prêmio Gulbenkian de Ciências Sociais. Obras publicadas: Culturas Juvenis; Sociologia da Vida Quotidiana; Consciência Histórica e Identidade; Ganchos, Tachos e Biscates. Jovens Trabalho e Futuro; Nos Rastos da Solidāo; Sexualidade e Afetos Juvenis; Lufa-lufa Quotidiana; Enredos Sexuais, Tradição e Mudança. E-mail: machado.pais@gmail.com

\section{Luciane De Conti}

Professora e pesquisadora da Pós-Graduação em Psicanálise, Clínica e Cultura, do Instituto de Psicologia e do Departamento de Psicanálise e Psicopatologia da Universidade Federal do Rio Grande do Sul (UFRGS). Doutora em Psicologia do Desenvolvimento pela UFRGS, com doutorado sanduíche na Université de Nantes, França. Suas pesquisas apresentam interface com as áreas de Psicanálise, Saúde Mental, Educação e Assistência Social e abrangem os temas: narrativas de si, políticas públicas, sofrimento psíquico e vulnerabilidades. Pesquisadora do GRIFARS-UFRN-CNPq. E-mail: luciane.conti@ufrgs.br

\section{Márcio Mori}

Professor de Comunicação e Expressão, Oficina de Leitura, Interpretação e Redação, Cinematografia na UNICARIOCA. Professor-tutor de Português Instrumental à distância do CEDERJ-UNIRIO. Doutorando em Educação na Universidade Federal Fluminense. Licenciado em Letras pela UNISAL. Pós-Graduação em Informática Educativa. E-mail: portuguesinstrumental@gmail.com 